\title{
BUILDING A POWERHOUSE
}

$\mathrm{T}$ he story of China's phenomenal growth in scientific output during the past three years can be told through the experience of eleven cities. Each has displayed impressive output, measurable in one way or another, as determined by analysis of Nature Index data from 2012 to 2014.

Four index metrics have been used to evaluate the performances of China's cities: article count (AC); fractional count (FC); collaboration score and weighted fractional count (WFC). (For a full explanation of these metrics see S190.)

Represented here in yellow are China's scientific heavyweights Beijing, Shanghai and Nanjing: the cities that have shown the highest total output. The index data also reveal some of the cities where total scientific output has been growing fastest - China's rising stars - are Xi'an, Chengdu and Hangzhou, shown in orange. Delving deeper into index data identifies Shenzhen, Beijing and Wuhan, represented in red, as the nation's industrial research powerhouses; where high scientific output is being used to generate economic return. Meanwhile, the cities most actively pursuing partnerships to advance scientific discoveries are Hefei, Tianjin and Hong Kong, in purple.

Data analysis by Larissa Kogleck

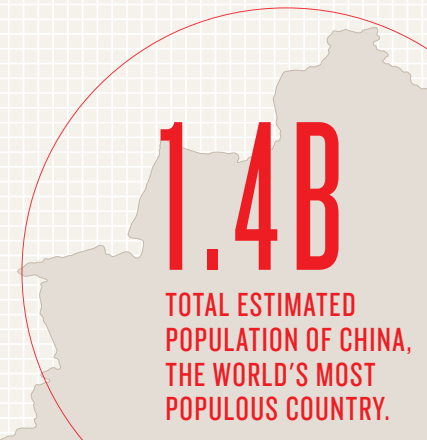

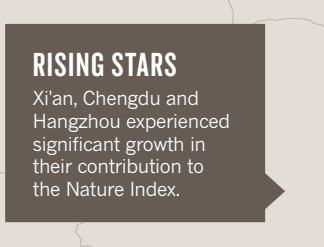
XI'AN $>2014$ WFC: 141 $>2013$ WFC: 95 $>2012$ WFC: 58

\section{CHENGDU}

$>2014$ WFC: 131 $>2013$ WFC: 107 $>2012$ WFC: 73

\section{(}
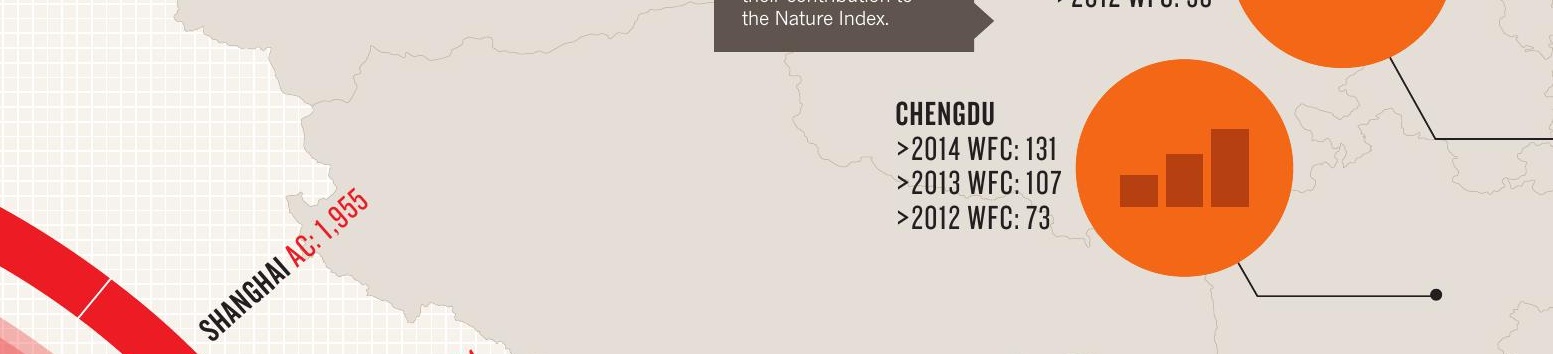


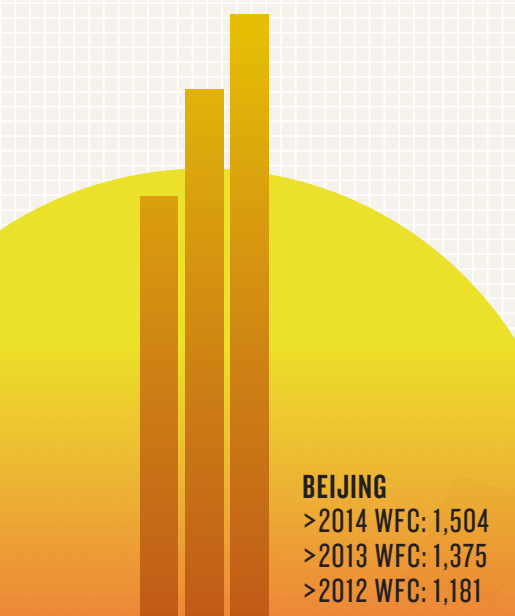

STRONGHOLDS

Beijing, Shangha

and Nanjing

continue to

dominate China's

scientific output.

\section{LEGEND}

Circle size is relative to WFC

in 2014 .

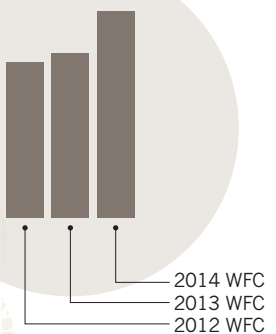

\section{EXPLORE CHINA}

Read more about the cities

behind China's rapid

scientific ascension.

STRONGHOLDS PAGE S176

RIIING StaRS PAGE S179

INDUSTRY HUBS P PAGE S184

COLlaborators \PAGE S187

NANJING

$>2014$ WFC: 388

$>2013$ WFC: 304

$>2012$ WFC: 286

FC: 255

$>2013$ WFC: 212

$>2012$ WFC: 179

$>2014$ WFC: 164

$>2013$ WFC: 168

$>2012$ WFC: 136

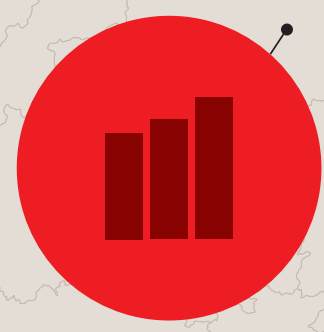

WUHAN

$>2014$ WFC: 257

$>2013$ WFC: 217

>2012 WFC: 192
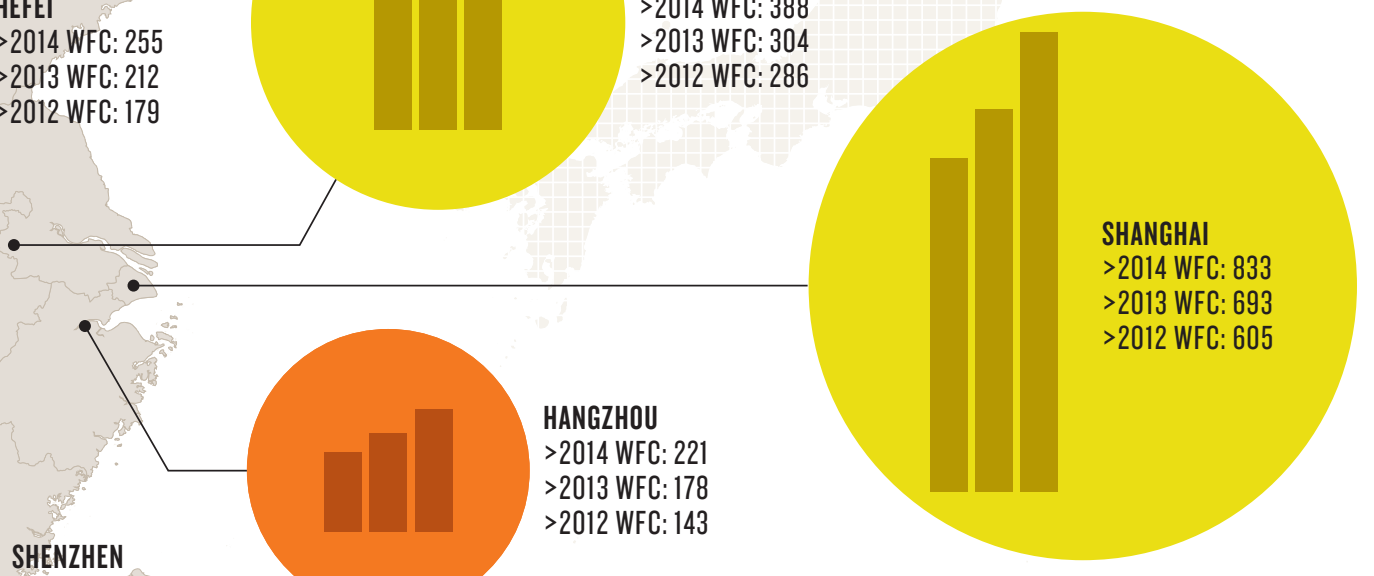

\section{HANGZHOU}

$>2014$ WFC: 221

$>2013$ WFC: 178

$>2012$ WFC: 143

SHANGHAI

$>2014$ WFC: 833

$>2013$ WFC: 693

$>2012$ WFC. 605

\section{INDUSTRY}

HUBS

Wuhan,

Shenzhen and

Beijing are

home to

corporations

that are making

a significant

contribution to

research in the

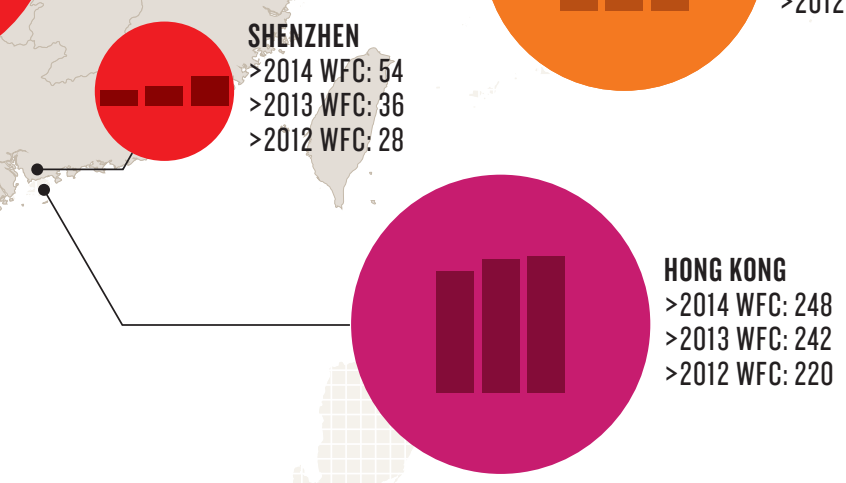

\section{COLLABORATORS}

Hong Kong, Hefei and

Tianjin have made the most

of collaborating with other

institutions in China and

the world. 